CZASOPISMO INŻYNIERII LĄDOWEJ, ŚRODOWISKA I ARCHITEKTURY JOURNAL OF CIVIL ENGINEERING, ENVIRONMENT AND ARCHITECTURE JCEEA, t. XXXIII, z. 63 (2/I/16), kwiecień-czerwiec 2016, s. 359-371

\author{
Magdalena WARZYBOK ${ }^{1}$
}

\title{
SYNTEZA ZEOLITÓW DO ADSORPCJI ACETONU
}

\begin{abstract}
Celem prowadzonych badań było uzyskanie efektywnych adsorbentów do usuwania acetonu z gazów odlotowych. Wybrano zeolit typu Y ze względu na jego wysoką termo stabilność umożliwiającą desorpcję zaadsorbowanego acetonu w temperaturach dochodzących do $1000^{\circ} \mathrm{C}$. Proces syntezy składał się z czterech etapów: (1) aktywacji termicznej surowego materiału, (2) starzenia mieszanin reakcyjnych w temperaturze otoczenia, (3) krystalizacji (wysokotemperaturowego ogrzewania składników) oraz (4) przemywania i suszenia produktu. Jako substraty wykorzystano naturalne materiały ilaste - bentonit $(B)$, haloizyt $(\mathrm{H})$ oraz kaolin $(\mathrm{K})$. Aby zapewnić odpowiedni stosunek molowy $\mathrm{Na}_{2} \mathrm{O}: \mathrm{SiO}_{2}: \mathrm{Al}_{2} \mathrm{O}_{3}: \mathrm{H}_{2} \mathrm{O}$ do syntezy zastosowano również krzemionkę $\left(\mathrm{SiO}_{2}\right)$ oraz roztwory chlorku $(\mathrm{NaCl})$ oraz wodorotlenku sodu $(\mathrm{NaOH})$. Podczas badań optymalizowano: temperaturę aktywacji, czas starzenia oraz czas i temperaturę etapu krystalizacji. Wpływ optymalizowanych parametrów na właściwości otrzymanych adsorbentów oceniano na podstawie: masy uzyskanego produktu, straty po prażeniu (LOI [\%]), stężenia jonów $\mathrm{Na}^{+}$ w przesączach poreakcyjnych $\left(C_{N a}[\mathrm{mg} / \mathrm{l}]\right)$ oraz pojemności adsorpcyjnej względem acetonu $\left(q_{e}[\mathrm{mg} / \mathrm{g}]\right)$. Optymalna temperatura aktywacji wyjściowych materiałów ilastych wynosi $600^{\circ} \mathrm{C}$. Podnoszenie temperatury aktywacji o kolejne $100^{\circ} \mathrm{C}$ skutkowało pogarszaniem właściwości adsorbentów. Wydłużenie czasu starzenia i krystalizacji, jak również podwyższenie temperatury etapu krystalizacji poprawia właściwości adsorpcyjne otrzymanych zeolitów. Optymalny czas etapu krystalizacji zależy od rodzaju materiału wyjściowego użytego do syntezy, temperatury aktywacji oraz czasu starzenia. Wydłużenie czasu starzenia mieszanin reakcyjnych pozwala na skrócenie czasu krystalizacji.
\end{abstract}

Słowa kluczowe: zeolity syntetyczne, haloizyt, bentonit, materiały ilaste, aceton, lotne związki organiczne

\section{Wprowadzenie}

Lotne Związki Organiczne (LZO) stanowią istotną grupę zanieczyszczeń, których obecność wpływa niekorzystnie na zdrowie ludzkie oraz na środowisko naturalne $[1,2]$. Jednym z podstawowych związków należących do LZO jest aceton, którego głównymi źródłami emisji są chemiczne procesy produkcyjne,

\footnotetext{
${ }^{1}$ Magdalena Warzybok, Politechnika Rzeszowska, al. Powstańców Warszawy 6, 35-959 Rzeszów, 177432408, lub Otto Engineering Polska Sp. z o.o.' ul. Połonińska 15, 35-083 Rzeszów, tel.: 726-104-604, e-mail: magdalena.warzybok@ottoindustries.com.pl
} 
spaliny samochodowe oraz rozpuszczalniki wykorzystywane do malowania oraz czyszczenia powierzchni metalowych [3]. Aceton może przyczyniać się do wystąpienia zaburzeń zdrowotnych u człowieka, np.: podrażnień oczu i układu oddechowego, nudności oraz wahań nastroju [4].

Usuwanie acetonu z gazów odlotowych przeprowadza się w procesie spalania termicznego, dopalania katalitycznego oraz biologicznego oczyszczania. Bezpośrednie zastosowanie metody termicznej wiąże się z wysokimi kosztami energetycznymi wynikającymi z dopalania dużych objętości gazu o niskim stężeniu zanieczyszczeń. Do zatężenia zanieczyszczeń i równoczesnego obniżenia kosztów procesu termicznego stosuje się proces adsorpcji. W przypadku dopalania katalitycznego występuje wysokie ryzyko tzw. zatrucia katalizatora, dlatego gaz musi być wstępnie oczyszczony z cząstek stałych i nie może zawierać m.in. związków siarki i fosforu oraz halogenków. Zastosowanie metody biologicznej wymusza konieczność chłodzenia gazów odlotowych (do temperatury z zakresy $30-35^{\circ} \mathrm{C}$ ), ze względu na wrażliwość drobnoustrojów [4, 6, 7]. Zupełnie odrębną grupę metod usuwania acetonu stanowią techniki wykorzystujące zjawiska elektryczne, np. szeroko opisywane metody oparte na plaźmie nietermicznej, w których plazma pochodzi ze źródeł opartych o wyładowania koronowe lub wyładowania $\mathrm{z}$ barierą dielektryczną (DBD) [7, 8, 9].

Alternatywną metodą zapewniającą jednocześnie odzysk acetonu są techniki adsorpcyjne. Powszechnie jako adsorbenty stosuje się węgiel aktywny [10], jednak istnieje wiele badań wskazujących na zastosowanie również krzemionki mezoporowatej [11, 12], grafenu, nanorurek węglowych [13], tlenku tytanu [14] oraz zeolitów syntetycznych $[15,16]$. O wyborze adsorbentu decyduje przede wszystkim jego cena, pojemność adsorpcyjna oraz termostabilność. Obecnie badania skupiają się na zeolitach syntetycznych. Są to krystaliczne, mikroporowate materiały zbudowane $\mathrm{z}$ tetraedrycznych jednostek $\mathrm{SiO}_{4} \mathrm{i} \mathrm{AlO}_{4}$ tworzących sieć porów o wymiarach molekularnych [17]. Poszczególne typy zeolitów syntetycznych różnią się strukturą determinowaną przez stosunek molowy $\mathrm{SiO}_{2} / \mathrm{Al}_{2} \mathrm{O}_{3}$. Rozróżnia się zeolity nisko (np. zeolit typu A $[18,19]$ ), średnio (np. zeolity typu X [20, 21] i Y [22, 23]) oraz wysokokrzemowe (np. zeolit typu ZSM [24]). Materiały te charakteryzują się trwałością struktury w temperaturach dochodzących do $1000^{\circ} \mathrm{C}$ [25], co umożliwia przeprowadzenie desorpcji termicznej zaadsorbowanych gazów i wielokrotne ich wykorzystanie. Mają dużą powierzchnię właściwą, dochodzącą do ok. 1000 [m²/g]6 [26], co przekłada się na dużą pojemność adsorpcyjną. Ze względu na te cechy znalazły zastosowanie do sorpcji jonów metali (np. $\mathrm{Pb}(\mathrm{II})$ [27], $\mathrm{Cr}(\mathrm{VI})$ [28], As(V) [29]), separacji związków, wymiany jonowej oraz w procesach katalitycznych [30]. Przykładowo fojazyt typu Y jest wykorzystywany głównie jako katalizator w procesie krakingu katalitycznego oraz jako adsorbent LZO z wilgotnych strumieni gazów odlotowych [31]. Natomiast drugi zeolit należący do grupy fojazytów, tj. zeolit typu $\mathrm{X}$ wykazuję wysoką zdolność adsorpcji kationów metali ciężkich oraz radionuklidów [32]. 
Proces syntezy zeolitów polega na wysokotemperaturowym ogrzewaniu składników krzemo- oraz glinonośnych z ewentualnym dodatkiem np. $\mathrm{NaOH}$, $\mathrm{NaCl}, \mathrm{Al}(\mathrm{OH})_{3}$ i $\mathrm{SiO}_{2}$, w celu uzyskania odpowiedniego stosunku molowego $\mathrm{Na}_{2} \mathrm{O}: \mathrm{SiO}_{2}: \mathrm{Al}_{2} \mathrm{O}_{3}: \mathrm{H}_{2} \mathrm{O}$. Jako składniki krzemonośne stosuje się m.in.: krzemionkę koloidalną i krzemian sodu, natomiast jako składniki glinonośne: izopropanolan glinu oraz glinian sodu [33, 34, 35]. Ze względu na wysoki koszt czystych substratów stosuje się naturalne materiały ilaste (np. haloizyt $[36,37]$ ) oraz materiały odpadowe (np. popioły lotne [38, 39], łupiny ryżowe [40], szlam papierowy [41]). Jakość otrzymanego produktu syntezy zależy od stosunku molowego $\mathrm{Na}_{2} \mathrm{O}: \mathrm{SiO}_{2}: \mathrm{Al}_{2} \mathrm{O}_{3}: \mathrm{H}_{2} \mathrm{O}$, temperatury i czasu aktywacji, czasu starzenia mieszaniny reakcyjnej oraz temperatury i czasu krystalizacji. Pierwszym etapem syntezy jest aktywacja termiczna materiału wyjściowego, którą przeprowadza się w temperaturach z zakresu $600-950^{\circ} \mathrm{C}[19,36,37,42,43,44]$. Następnie przeprowadza się proces starzenia mieszaniny reakcyjnej $\mathrm{w}$ temperaturze od 20 do $50{ }^{\circ} \mathrm{C}$ przez okres od kilku do kilkudziesięciu godzin $[45,46]$. Ostatnim etapem jest krystalizacja mieszaniny reakcyjnej prowadzona zazwyczaj $\mathrm{w}$ temperaturze $100^{\circ} \mathrm{C}$ przez okres od 24 do $48 \mathrm{~h}[40,45,47]$.

Celem przeprowadzonych badań była synteza zeolitu typu Y do adsorpcji par acetonu. Określono wpływ rodzaju zastosowanego materiału wyjściowego oraz warunków poszczególnych etapów syntezy na właściwości adsorpcyjne otrzymanego materiału.

\section{Synteza zeolitów}

\subsection{Materiały i odczynniki}

Do syntezy zeolitów wykorzystano trzy materiały ilaste dostarczone przez firmę BioDrain pod następującymi nazwami handlowymi: bentonit (B), haloizyt (H) oraz kaolin (K). Skład chemiczny minerałów (Tabela 1.) określono metodą spektroskopii XRF. Pomiary wykonano z pastylki (średnica $27 \mathrm{~mm}$ ) sprasowanej ze zmielonego, wysuszonego i homogenicznego materiału. Chlorek sodu oraz żel krzemionkowy wyprodukowane zostały przez firmę Chepmur, natomiast wodorotlenek sodu (CZDA) przez firmę POCH.

Tabela 1. Skład chemiczny surowych materiałów ilastych

Table 1. Chemical composition of raw clay materials

\begin{tabular}{c|cccccccc}
\hline Składnik & & $\mathbf{S i O}_{\mathbf{2}}$ & $\mathbf{A l}_{\mathbf{2}} \mathbf{O}_{\mathbf{3}}$ & $\mathbf{F e}_{\mathbf{2}} \mathbf{O}_{\mathbf{3}}$ & $\mathbf{T i O}_{\mathbf{2}}$ & $\mathbf{C a O}$ & $\mathbf{M g O}$ & $\mathbf{K}_{\mathbf{2}} \mathbf{O}$ \\
\hline \multirow{2}{*}{ Zawartość } & $\mathrm{B}$ & 61,6 & 20,0 & 3,0 & 0,3 & 2,2 & 3,1 & 0,7 \\
{$[\%]$} & $\mathrm{H}$ & 33,4 & 28,2 & 23,0 & 3,9 & 0,6 & 0,4 & 0,3 \\
& $\mathrm{~K}$ & 52,5 & 34,5 & 0,8 & 0,5 & 0,1 & 0,1 & 0,6 \\
\hline
\end{tabular}




\subsection{Proces syntezy}

Syntezę zeolitów Y prowadzono w czterech etapach:

(1) Aktywacja surowego materiału wyjściowego. Haloizyt i kaolin aktywowano termicznie (SNOL 8:2/1000) przez $5 \mathrm{~h} \mathrm{w}$ temperaturze: 600, 700, 800 lub $900^{\circ} \mathrm{C}$. Bentonit wypalano w piecu przez $6 \mathrm{~h} \mathrm{w}$ temperaturze $600^{\circ} \mathrm{C}$. $[20,22]$.

(2) Starzenie mieszaniny reakcyjnej. Do aktywowanych materiałów dodano stały $\mathrm{SiO}_{2}, 20 \% \mathrm{NaCl}$ oraz $20 \% \mathrm{NaOH}$ celem uzyskania założonego stosunku molowego $\mathrm{Na}_{2} \mathrm{O}: \mathrm{SiO}_{2}: \mathrm{Al}_{2} \mathrm{O}_{3}: \mathrm{H}_{2} \mathrm{O}$ (10:1:10:150). Mieszaniny pozostawiono w temperaturze otoczenia na określony czas, od 18 do $336 \mathrm{~h}$.

(3) Krystalizacja zeolitów syntetycznych w podwyższonej temperaturze, która w zależności od zastosowano materiału wyjściowego wynosiła 80 lub $100^{\circ} \mathrm{C}$. Określono również czas prowadzenia krystalizacji oraz metodę ogrzewania mieszanin reakcyjnych. Próbki ogrzewano w łaźni wodnej (LABO PLAY TERMSTAR SERIA T) lub suszarce laboratoryjnej (POLEKO SLW32 EKO) w czasie od 1 do $48 \mathrm{~h}$.

(4) Płukanie produktów syntezy wodą demineralizowaną do uzyskania neutralnego odczynu $\mathrm{pH}$, suszenie w temperaturze $110^{\circ} \mathrm{C}$ do stałej masy. Wodę po płukaniu zbierano i poddano analizie na zawartość jonów $\mathrm{Na}^{+}$(metoda fotometrii płomieniowej, aparat BWB XP).

Otrzymane produkty syntezy ważono (RADWAG AS 60/220/C/2) i wypalano w piecu muflowym (SNOL 8.2/1100) przez $1 \mathrm{~h}$ w $800^{\circ} \mathrm{C}$, w celu określeniu straty po prażeniu (LOI), zgodnie z równaniem:

$$
\operatorname{LOI}(\%)=\frac{m_{1}-m_{2}}{m_{1}} \cdot 100 \%
$$

gdzie: $m_{1}$ - masa przed wypaleniem;

$m_{l}$ - masa po wypaleniu.

\subsection{Adsorpcja acetonu}

Adsorpcję acetonu przeprowadzono $\mathrm{w}$ specjalnie przygotowanej instalacji laboratoryjnej [48], udostępnionej przez firmę Otto Engineering Polska Sp. z o.o. W skład instalacji wchodziły: butla z mieszaniną acetonu w azocie o stężeniu 208 ppm, kolumna wypełniona danym adsorbentem oraz przepływomierz. Stężenie acetonu na wyjściu z kolumny adsorpcyjnej mierzono on-line za pomocą chromatografu gazowego (Thermo Scientific TRACE 1300 GC). Wynikiem pomiaru była krzywa przebicia obrazująca zmianę stężenia na wyjściu z kolumny. Ilość zaadsorbowanego acetonu $q_{e}[\mathrm{mg} / \mathrm{g}]$ wyznaczono metodą całkowania numerycznego. 


\section{Otrzymane wyniki}

\subsection{Wpływ temperatury aktywacji}

Wpływ temperatury aktywacji haloizytu i kaolinu na pojemność adsorpcyjną $\left(q_{e}\right)$ przedstawiono na Rysunku 1. Jak widać, wraz ze wzrostem temperatury aktywacji następuje spadek efektywności adsorpcji acetonu. Największą efektywność uzyskano dla temperatury $600^{\circ} \mathrm{C}$. Wynosiła ona dla haloizytu, którego czas krystalizacji wynosił $48 \mathrm{~h}$ ok. 30 [mg/g], a dla kaolinu, którego czas krystalizacji wynosił 24h ok. 60 [mg/g].

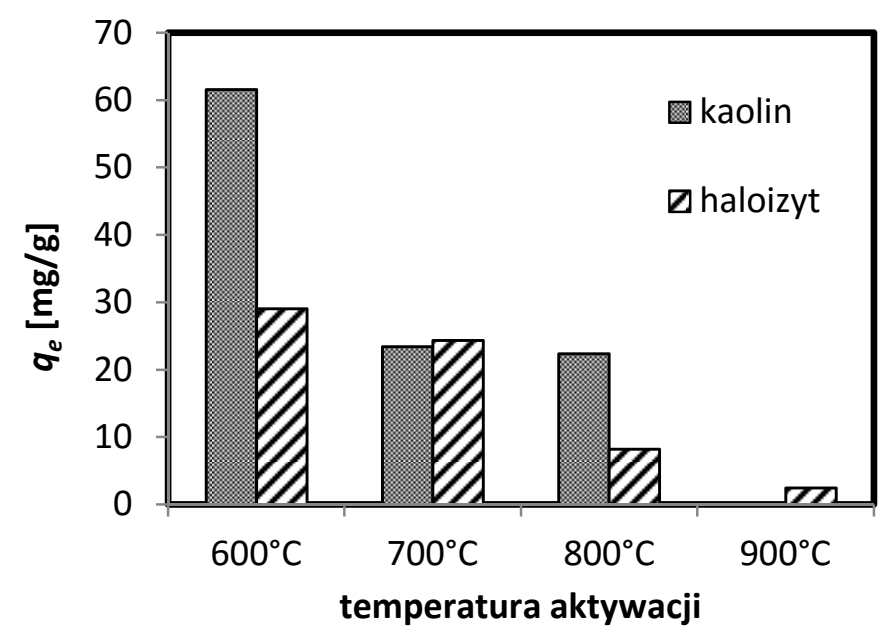

Rys. 1. Wpływ temperatury aktywacji na pojemność adsorpcyjną acetonu

Fig. 1. Effect of the temperature of activation on the adsorption capacity of the acetone

Na Rysunku 2. przedstawiono wartości straty po prażeniu w zależności od czasu krystalizacji próbek kaolinu aktywowanych w 600 oraz $700^{\circ} \mathrm{C}$. Widać proporcjonalny wzrost wartości $L O I$ [\%] wraz z wydłużaniem czasu krystalizacji. Zależność ta potwierdza wzrost stopnia przereagowania substratów syntezy wraz z czasem krystalizacji. Po 48h krystalizacji wartość LOI wynosiła ok. 17\% dla materiału aktywowanego $\mathrm{w} 600^{\circ} \mathrm{C}$ oraz ok. $12 \%$ dla materiału aktywowanego w $700^{\circ} \mathrm{C}$. 


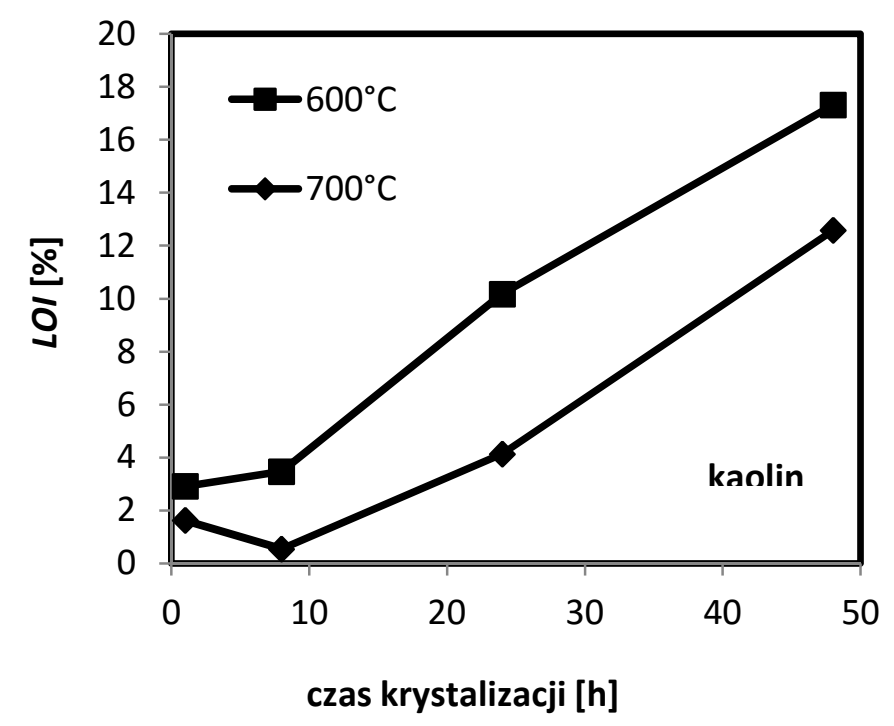

Rys. 2. Wpływ temperatury aktywacji oraz czasu krystalizacji na wartość $L O I$ [\%]

Fig. 2. Effect of the activation temperature and the crystallization time on the value of $L O I[\%]$

\subsection{Wpływ czasu starzenia}

Nie zaobserwowano liniowej zależności pomiędzy przyrostem masy adsorbentów a wzrostem czasów krystalizacji i starzenia (Rysunek 3.). Z uzyskanej zależności wynika, ze wydłużenie czasu starzenia pozwala na skrócenie czasu krystalizacji. Ośmiogodzinna synteza materiału poddawanego starzeniu 336h pozwala na uzyskania porównywalnego wzrostu masy adsorbentu (ok. 75\%) co 24-godzinna synteza materiału poddawanego starzeniu przez 264h (ok. 80\%). 


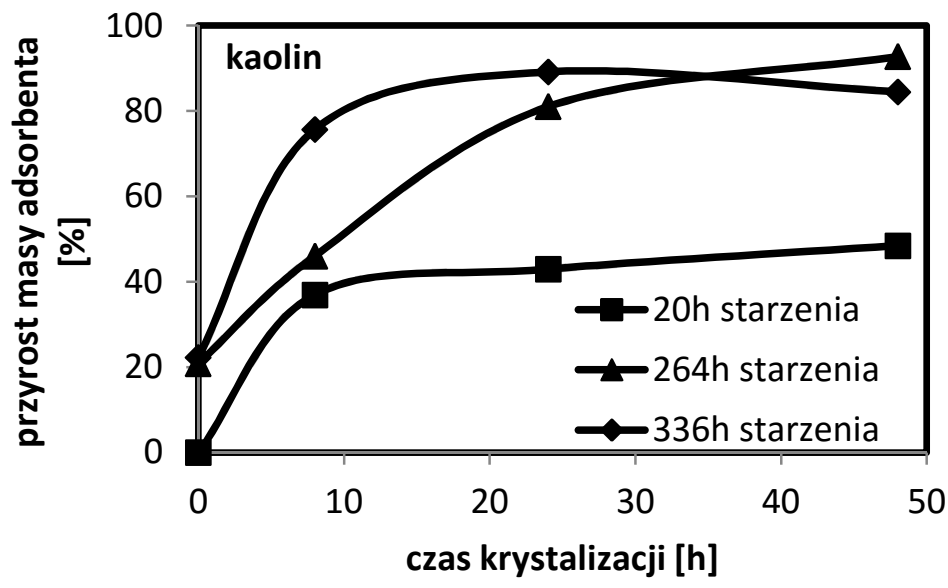

Rys. 3. Wpływ czasu starzenia oraz czasu krystalizacji na przyrost masy adsorbentów [\%]

Fig. 3. Effect of the aging and crystallization time on the mass increase of adsorbents [\%]

\subsection{Wpływ czasu krystalizacji}

Wpływ czasu krystalizacji na właściwości adsorbentów powstałych na bazie bentonitu przedstawiono na Rysunkach 4-5. Jak widać dla dłuższych czasów krystalizacji jest większa strata po prażeniu ( $10 \%$ po $24 \mathrm{~h}$ reakcji) oraz mniejsze stężenie jonów $\mathrm{Na}^{+}$w przesączach poreakcyjnych. Dla próbki, która krystalizowała przez 24h, uzyskano największa efektywność adsorpcji acetonu (Rysunek 5.). Prawdopodobnie dalsze wydłużenie czasu krystalizacji spowodowałoby dalszy wzrost efektywności adsorpcji, podobnie jak to uzyskano dla haloizytu (Rysunek 5.).
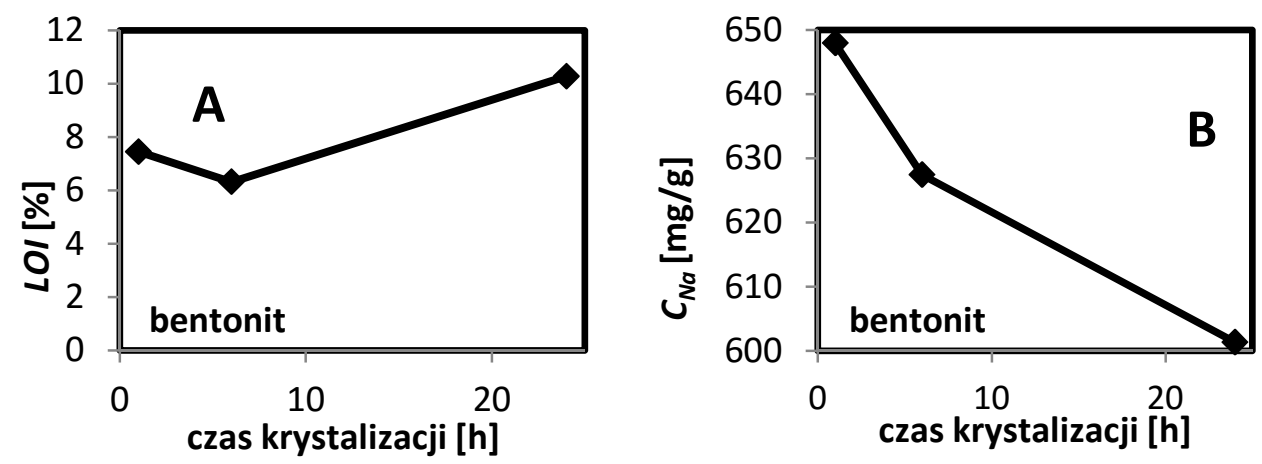

Rys. 4. Wpływ czas krystalizacji na (A) stratę po prażeniu LOI [\%], (B) stężenie jonów $\mathrm{Na}^{+} C_{\mathrm{Na}}[\mathrm{mg} / \mathrm{l}]$

Fig. 4. Effect of crystallization time on (A) the loss of ignition $L O I$ [\%], (B) $\mathrm{Na}^{+}$ion concentration $C_{N a}[\mathrm{mg} / \mathrm{l}]$ 


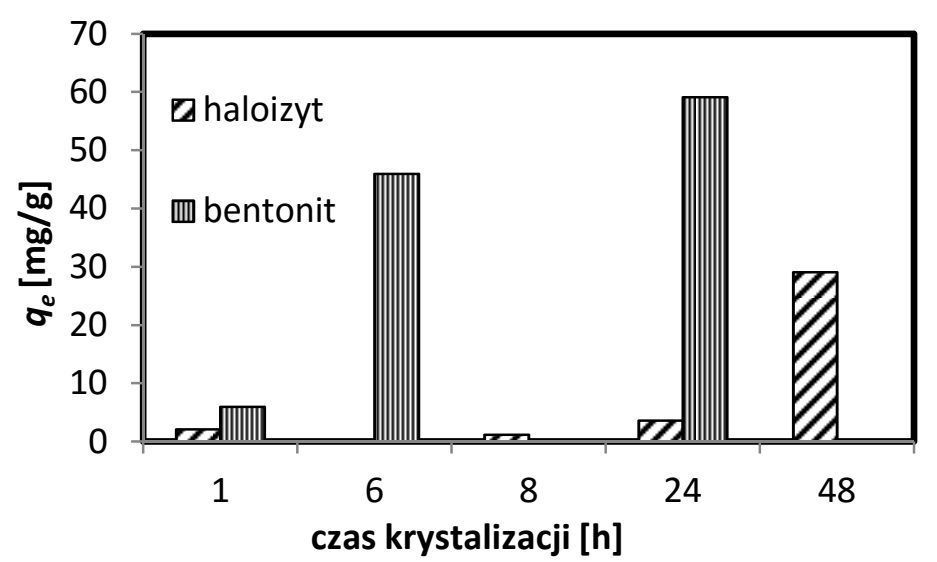

Rys. 5. Wpływ czasu krystalizacji na pojemność adsorpcyjną acetonu

Fig. 5. Effect of the crystallization time on the adsorption capacity of the acetone

Wpływ czasu krystalizacji na właściwości adsorbentów syntezowanych z kaolinu przedstawiono na Rysunkach 2, 3 oraz 6. Wydłużenia czasu krystalizacji wpłynęło na przyrost masy produktów syntezy oraz na wzrost wartości straty po prażeniu (dla próbek aktywowanych w 600 oraz $700^{\circ} \mathrm{C}$ ). Na szybkość wzrostu obu parametrów znaczący wpływ miała temperatura aktywacji materiału surowego.

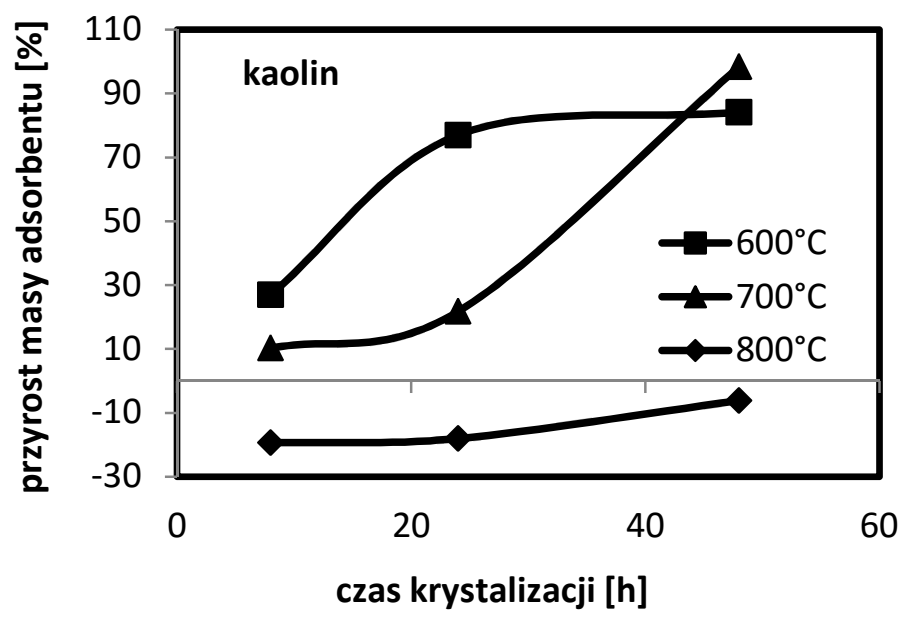

Rys. 6. Wpływ temperatury aktywacji oraz czasu krystalizacji na przyrost masy adsorbentów [\%]

Fig. 6. Effect of the activation temperature and the crystallization time on the mass increase of adsorbents [\%] 


\subsection{Wpływ temperatury krystalizacji}

Proces krystalizacji zeolitu z bentonitu prowadzono w dwóch temperaturach: $80 \mathrm{i} 100^{\circ} \mathrm{C}$. Wpływ temperatury krystalizacji na pojemność adsorpcyjną produktu względem acetonu $\left(q_{e}\right)$ przedstawiono na Rysunku 7. Dla próbki ogrzewanej przez $24 \mathrm{~h} \mathrm{w} 80^{\circ} \mathrm{C}$ wyznaczana pojemność adsorpcyjna wyniosła ok. $60[\mathrm{mg} / \mathrm{g}]$, natomiast dla próbki ogrzewanej przez taki sam czas w $100^{\circ} \mathrm{C}$ pojemność adsorpcyjna wzrosła dwukrotnie. Dalsze obniżenie temperatury poniżej $80^{\circ} \mathrm{C}$ skutkowałoby uzyskaniem wyłącznie amorficznej frakcji [42].

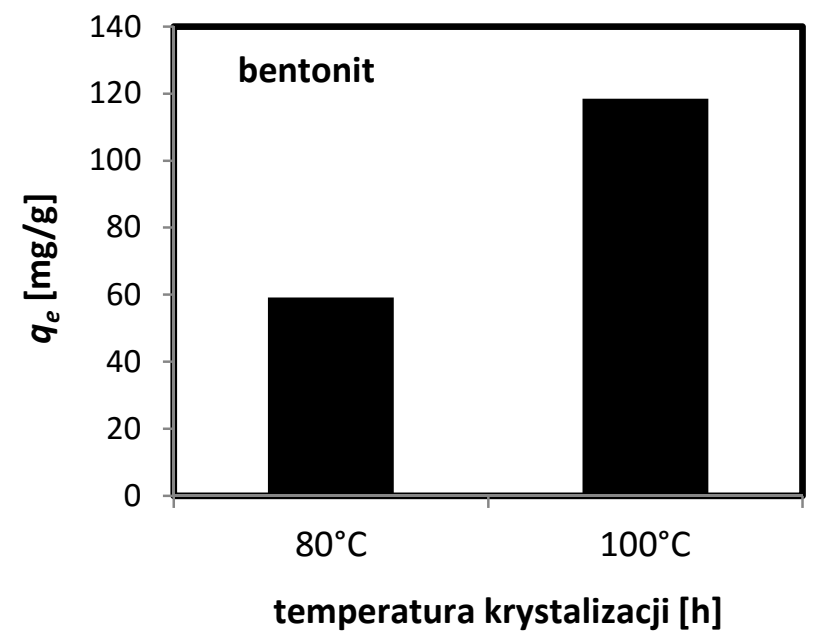

Rys. 7. Wpływ temperatury krystalizacji na pojemność adsorpcyjną acetonu

Fig. 7. Effect of the crystallization temperature on the adsorption capacity of the acetone

\section{Podsumowanie}

Właściwości adsorpcyjne zeolitów uzyskanych na drodze syntezy zależą od: temperatury aktywacji termicznej materiału surowego, czasu starzenia reagentów oraz temperatury i czasu etapu krystalizacji. Najodpowiedniejsza temperatura aktywacji termicznej stosowanych materiałów ilastych wynosi $600^{\circ} \mathrm{C}$. Dla tej temperatury maksymalne pojemności adsorpcyjne wynosiły dla kaolinu i haloizytu odpowiednio 61,6 oraz $29,1[\mathrm{mg} / \mathrm{g}]$. Dalsze podnoszenie temperatury aktywacji skutkuje obniżeniem wartości straty po prażeniu oraz pogorszeniem właściwości adsorpcyjnych. $\mathrm{Z}$ kolei podwyższenie temperatury krystalizacji próbek otrzymanych z bentonitu (z 80 do $100^{\circ} \mathrm{C}$ ) powoduje dwukrotny wzrost pojemności adsorpcyjnej acetonu (z ok. 60 do ok. 120 [mg/g]). Wartość ta jest porównywalna do ilości acetonu adsorbowanego na komercyjnych węglach aktywnych (ok. 90 [mg/g]) [49]. 
Wartość optymalnego czasu etapu krystalizacji zależała od stosowanego materiału wyjściowego, jego temperatury aktywacji termicznej oraz czasu starzenia mieszaniny reakcyjnej. Wydłużenie czasu starzenia mieszanin reakcyjnych pozwala na skrócenie czasu krystalizacji. Ma to ważny aspekt ekonomiczny, ponieważ etap starzenia prowadzono w temperaturze otoczenia bez ponoszenia kosztów energetycznych, natomiast proces krystalizacji prowadzono w wysokich temperaturach, co wiązało się z zużyciem energii.

\section{Podziękowanie}

Składam podziękowania firmie OTTO Engineering Polska Sp. z o. o. za pokrycie części kosztów badań oraz udostępnienie infrastruktury naukowo-badawczej.

\section{Literatura}

[1] Ramirez N., Cuadras A., Rovira E., Borrull F., Marce R.M.: Chronic risk assessment of exposure to volatile organic compounds in the atmosphere near the largest Mediterranean industrial site. Environmental International, no. 39, 2012, pp. 200-209.

[2] Stojic A.,Maletic D.,Stanisic Stojic S., Mijic Z., Sostaric A.: Forecasting of VOC emissions from traffic and industry using classification and regression multivariate methods. Science of the Total Environment, no. 521-522, 2015, pp. 19-26.

[3] Zheng Ch, Zhu X., Gao X., Liu L., Chang Q., Luo Z.: Experimental study of acetone removal by packed-bed dielectric barries discharge reactor. Journal of Industrial and Engineering Chemistry, 20, 2014, 2761-2768.

[4] Das S., Majumdar S., Kumar R., Ghosh S., Biswas D.: Thermodynamic analysis of acetone sensing in $\mathrm{Pd} / \mathrm{AlGaN} / \mathrm{GaN}$ heterostructure Schottky diodes at low temperatures, Scripta Materialia. 113, 2016, 39-42.

[5] Straszko J., Parus W., Paterkowski W.: Kinetyka reakcji spalania domieszek organicznych na katalizatorach niskotemperaturowych. Inż. Ap. Chem. 2013, 52, 6, 561-562.

[6] Wnęk B.: Rozkład lotnych związków organicznych w wyładowaniu koronowym.

[7] Zhu X., Gao X., Yu X., Zheng Ch., Tu X.: Catalyst screening for acetone removal in a single-stage plasma-catalysis system. Catalysis Today, 256, 2015, 108-14.

[8] Hołub M., Kalisiak S., Jakobowski T.: Źródła plazmy nietermicznej dla technologii ochrony środowiska. Zeszyty Naukowe Wydziału Elektrotechniki i Automatyki Politechniki Gdańskiej, Nr 27, 2010, 27-30.

[9] Jaworek A., Czech T., Krupa A., Antes T.: Kierunki rozwoju elektrostatycznych urządzeń do oczyszczania gazów odlotowych. V Konferencja Naukowo-Techniczna ELEKTROFILTRY’2000, Kraków, 14-16 września 2000, 59-68.

[10] Gales L., Mendes A., Costa C.: Hysteresis in the cyclic adsorption of acetone, ethanol and ethyl acetate on activated carbon. Carbon, 38, 2000, 1083-1088.

[11] Hung Ch., Bai H., Karthik M.: Ordered mesoporous silica particles and Si-MCM-41 for the adsorption of acetone: A comparative study. Separation and Purification Technology, 64, 2009, 265-272. 
[12] Ushiki I., Ota M., Sato Y., Inomata H.: VOCs (acetone, toluene, and n-hexane) adsorption equilibria on mesoporous silica (MCM-41) over a wide range of supercritical carbon dioxide conditions: Experimental and theoretical approach by the Dubinin-Astakhov equation. Fluid Phase Equalibria, 403, 205, 78-84.

[13] He Y., Zhang N., Wu F., Xu F., Liu Y., Gao J.: Graphene oxide foams and their excellent adsorption ability for acetone gas. Materials Research Bulletin, 48, 2013, 3553-3558.

[14] Chen Q., Zhu W., Hou X., Xu K.: Density funcional theory study of the adsorption of acetone on the pure and transition metal doped $\left(\mathrm{TiO}_{2}\right)_{38}$ clusters. Vacuum, 119, 2015, 123-130.

[15] D.-G. Lee, J.-H. Kim, C.-H., Lee, Adsorption and thermal regeneration of acetone and toluene vapours in dealiminated Y-zeolite bed, Separation and Purification Technology, 77, 2011, 312-324.

[16] Lee S.-W., Park H.-J., Lee S.-H., Lee M.-G.: Comparison of adsorption characteristics according to polarity difference of acetone and toluene vapor on silica-alumina fixed-bed reactor. Journal of Industrial and Engineering Chemistry, 14, 2008, 1017.

[17] Rasouli M., Yaghobi N., Chitsazan S., Sayyar M. H.: Effect of nano crystalline zeolite $\mathrm{Na}-\mathrm{Y}$ on meta-xylene separation. Microporous and Mesoporous Materials, no. 152, 2012, pp. 141-147.

[18] Zhao Y., Zhang B., Zhang X., Wang J., Liu J., Chen R.: Preparation of highly ordered cubic NaA zeolite from halloysite mineral for adsorption of ammonium ions. Journal of Hazardous Materials, 178, 2010, 658-664.

[19] Zhou Z., Jin G., Liu H., Wu J., Mei J.: Crystallization of zeolite A from coal kaolin using a two-step method. Applied Clay Science, 97-98, 2014, 110-114.

[20] Mezni M., Hamzaoui A., Hamdi N., Srasra E.: Synthesis of zeolites from low-grade Tunisian natural illite by two different methods. Applied Clay Science, 52, 2011, 209-218.

[21] Szala B., Turek P., Jeleń A., Bajda T.: Synteza i właściwości sorpcyjne organozeolitów. Inżynieria Środowiska, Nr 30, 2013, 5-12.

[22] Charkhi A., Kazemeini M., Ahmadi S.J., Kazemian H.: Fabrication of granulated $\mathrm{NaY}$ zeolite nanoparticles using a new method and study the adsorption properties. Powders Technology, 231, 2012, 1-6.

[23] Mohammed A.H.A.K., Karim S., Rahman A.M.: Characterization and Cracking Activity of Zeolite Prepared from Local Kaolin. Iraqi Journal of Chemical and Petroleum E-+-+ngineering, Vol.11, No.2, 2010, 35-42.

[24] Dedecek J., Balgová V., Pashkova V., Klein P., Wichterlová B.: Synthesis of ZSM5 Zeolites with Defined Distribution of Al Atoms in the Framework and Multinuclear MAS NMR Analysis of the Control of Al Distribution. Chem. Mater., 2012, 24 (16), 3231-3239.

[25] Trigueiro F.E., Monteiro D.F.J., Zotin F.M.Z., Falabella Sousa-Aguiar E.: Thermal stability of $\mathrm{Y}$ zeolites containing different rare earth cations. Journal of Alloys and Compounds, 344, 2002, 337-341

[26] Jabłońska M., Król A., Kukulska-Zając E., Tarach K., Girman V., Chmielarz L., Góra-Marek K.: Zeolites Y modified with palladium as effective catalysts for low- 
temperature methanol incineration. Applied Catalysis B: Environmental,166-167, 2015, 353-365.

[27] Anari-AnarakiM., Nezamzadeh-Ejhieh A.: Modification of an Iranian clinoptililite nano-particles by hexadecyltrimethyl ammonium cationic surfactant and dithizone for removal of $\mathrm{Pb}(\mathrm{II})$ from aqueous solution. Journal of Colloid and Interface Dcience, Vol. 440, 2015, 272-281.

[28] Thanos A.G., Katsou E., Malamis S., Psarras K., Pavlatou E.A., Haralambous K.J.: Evaluation of modified mineral performance for chromate sorpion from aqueous solutions. Chemical Engineering Journal, Vol. 211-212, 2012, 77-88.

[29] Chutia P., Kato S., Kojima T., Satokawa S.: Adsorption of As(V) on surfactant modified natural zeolites. Journal of Hazardous Material, 162, 2009, 204-211.

[30] Zhang J., Burke N., Zhang S., Liu K., Pervukhina M.: Thermodynamic analysis of molecular simulations of $\mathrm{CO}_{2}$ and $\mathrm{CH}_{4}$ adsorption in FAU zeolites. Chemical Engineering Science, no. 113, 2014, pp. 54-61.

[31] Karami D., Rohani S.: Synthesis of pure zeolite Y using soluable silicate, a twolevel factorial experimental design. Chemical Engineering and Processing, 48, 2009, 1288-1292

[32] Dere Ozdemir O., Piskin S.: Zeolite X Synthesis with Different Sources. IJCEBS, Vol.1, 2013, 229-232.

[33] Huang Y., Wang K., Dong D., Li D., Hill M.R., Hill A.J., Wang H.: Synthesis of hierarchical porous zeolite $\mathrm{NaY}$ particles with controllable particle size. Microporous and Mesoporous Materials, no. 127, 2010, pp. 167-175.

[34] Sang S., Liu Z., Tian P., Liu Z., Qu L., Zhang Y.: Synthesis of small crystals zeolite NaY. Materials Letters, 60, 2006, 1131-1133.

[35] Zhang X., Tong D., Zhao J., Li X.: Synthesis of NaX zeolite at room temperaturę and its characterization. Materials Letters, 104, 2013, 80-83.

[36] Gougazeh M., Buhl J.-Ch.: Synthesis and characterization of zeolite A by hydrothermal transformation of natural Jordanian kaolin. Journal of the Association of Arab Universities for Basic and Applied Sciences. 2014, 15, 35-42.

[37] Gualtieri A.F.L Synthesis of sodium zeolite from a natural halloysite. Phys. Chem. Minerals, 2001, 28, 719-728.

[38] Grela A, Hebda M., Łach M., Mikuła J.: Thermal behavior and physical characteristic of synthetic zeolite from CFB-coal fly ash. Microporous and Mesoporous Materials, 220, 2016, 155-162.

[39] Wdowin M., Baran P., Panek R., Zarębska K., Franus W.: Analiza możliwości oczyszczania gazów wylotowych $\mathrm{z} \mathrm{Hg}^{0} \mathrm{i} \mathrm{CO}_{2}$ na zeolitach syntetycznych otrzymanych z popiołów lotnych. Rocznik Ochrona Środowiska, 17, 2015, 1306-1319.

[40] Khabuanchalad S., Khemthong P., Prayoonpokarach S., Wittayakun J.: Transformation of zeolite $\mathrm{NaY}$ synthesized from rice husk silica o NaP during hydrothermal synthesis. Suranaree J. Sci. Technol., 15(3), 2008, 225-231.

[41] Wajima T., Haga M., Kuzawa K., Ishimoto H., Tamada O., Ito K., Nishiyama, Downs R.T., Rakovan J.F.: Zeolite synthesis from paper sludge ash at low temperature $\left(90^{\circ} \mathrm{C}\right)$ with addition of diatomite, Journal of Hazardous Materials, B132, 2006, 244-252. 
[42] Chen Ch., Park D.-W., Ahn W.-S.: CO2 capture using zeolite 13X prepared from bentonite. Applied Surface Science, 2014, Vol.292, 63-67.

[43] Maia A.A.B., Neves R.F., Angelica R.S., Pollmann H.: Synthesis, optimisation and characterization of the zeolite $\mathrm{NaA}$ using kaolin waste from the Amazon Region. Production of Zeolites KA, MgA and CaA. Applied Clay Science, 108, 2015, 55-60.

[44] Musyoka N.M, Missengue R., Kusisakana M., Petrik L.F.: Conversion of South African clays into high quality zeolites. Applied Clay Science, 2014, Vol. 97-98, 182-186.

[45] Htay M.M., Oo M.M.: Preparation of Zeolite Y Catalyst for Petroleum Cracking. World Academy of Science, Engineering and Technology, 48, 2008, 114-120.

[46] Johnson E.B.G., Arshad S.E.: Hydrothermally synthesized zeolites based on kaolinite: A review. Applied Clay Science, 97-98, 2014, 215-221.

[47] Bo W., Hongzhu M.: Factors affecting the synthesis of microsized NaY zeolite. Microporous and Mesoporous Materials, 25, 1998, 131-36.

[48] Pliś I., Prokop W., Petrus R., Warchoł J.: Sorption of acetone onto clay materials. 12 Scientific Conference POL-EMIS, Karpacz 4-7 June 2014.

[49] Pliś I., Prokop W., Petrus R., Warchoł J. Adsorption of gaseous pollutants on zeolitic minerals. Przemysł Chemiczny, 2015, 94/2, 186-190.

\section{SYNTHESIS OF ZEOLITES TO THE ADSORPTION OF ACETONE}

\section{S u m m a r y}

The aim of the research was to study the synthesis of zeolites for adsorbing acetone. The synthesis process consisted of four stages: (1) thermal activation of the raw material; (2) aging of the reaction mixtures at the ambient temperature; (3) crystallization (at high temperatures); and (4) washing and drying the products. As substrates of the synthesis (silica and aluminium sources) three natural clay materials were used - bentonite $(\mathrm{B})$, halloysite $(\mathrm{H})$ and koalin $(\mathrm{K})$. During the synthesis we also used silica $\left(\mathrm{SiO}_{2}\right)$, sodium chloride and sodium hydroxide.

During the examinations, the following parameters of the process were optimized: the temperature of the thermal activation of the raw material; the time of aging the reagents; and the time and the temperature of the crystallization stage. The influence of these optimized parameters on properties of the received adsorbents was assessed based on the following values: growth of the product mass; loss of ignition $(\mathrm{LOI}[\%])$; content of $\mathrm{Na}^{+}$cations in the filtrate $\left(C_{\mathrm{Na}}[\mathrm{mg} / \mathrm{l}]\right)$; and the adsorption capacity for acetone $\left(q_{e}[\mathrm{mg} / \mathrm{g}]\right)$.

Based on the achieved results, we can state, that the optimal temperature for the thermal activation of used clay materials is $600{ }^{\circ} \mathrm{C}$. As expected extending the time and increasing the temperature of the crystallization stage influenced the improvement of the properties of the adsorbents. Depending on the initial material, as well as the temperature of the activation and the time of aging, the optimum time for the crystallization stage was different.

Keywords: synthetic zeolites, halloysite, bentonite, clay materials, acetone, volatile organic compound

Przestano do redakcji: 24.11.2014 r.

Przyjęto do druku:1.03.2016 r.

DOI: $10.7862 / \mathrm{rb} .2016 .137$ 
